\title{
Is imagery vividness a determinant factor in creativity?
}

\author{
ALFREDO CAMPOS and MARIA ANGELES GONZALEZ \\ University of Santiago de Compostela, Santiago de Compostela, Spain
}

\begin{abstract}
We evaluated the contribution made by imagery vividness to creativity in a sample of university students from different disciplines. Imagery vividness explained $6 \%$ of the variance in creativity in fine arts students, $9 \%$ in mathematics students, $10 \%$ in geography and history students, and $7 \%$ overall. We discuss our results and propose new lines of research.
\end{abstract}

Many theorists in psychology have argued that imagery plays an important role in the creative process (Campos \& Pérez, 1989; Ernest, 1977; Forisha, 1978; Schmeidler, 1965; Shaw, 1985; Sheehan, McConkey, \& Law, 1978); however, research has not provided clear support for this hypothesis.

Khatena (1975) found significant correlations between visual, auditory, and cutaneous imagery vividness, as measured by the Betts Questionnaire Upon Mental Imagery (QMI; Betts, 1909; revised by Sheehan, 1967), and creativity, as measured by the Something About Myself test (SAM; Khatena, 1971). When the What Kind of Person Are You? test (Torrance \& Khatena, 1970) was used as a measure of creativity, however, Khatena found significant correlations only with the visual and cutaneous imagery vividness of the QMI.

Sheehan et al. (1978) correlated scores on the Creative Imagination Scale (Wilson \& Barber, 1976) with those on the Betts QMI and the Gordon Test of Visual Imagery Control (Richardson, 1969). A significant correlation was found between creative imagination and imagery control for 208 women. However, for 95 men, creative imagination correlated significantly only with imagery vividness. Forisha (1978) obtained significant correlations between scores on the Betts QMI and performance on the Unusual Uses tests only for women.

Rhodes (1981) used the Torrance Tests of Creative Thinking (Torrance, 1974) as a measure of creativity, and the QMI as a measure of imagery vividness. He found significant correlations between creativity and both visual and auditory imagery vividness. Shaw and DeMers (1986) used the Vividness of Visual Imagery Questionnaire, the Visual Memory Test, the Test of Visual Imagery Control, and several scales of the Torrance Tests of Creative Thinking. They yielded significant correlations between scores on the imagery tests and on some scales of the Torrance test, but not on others. Shaw and Belmore (198283 ) found a relationship between creativity and some, but

Correspondence may be sent to A. Campos, University of Santiago de Compostela, Dpt. Psicología Básica, Santiago de Compostela, Spain. not all, measures of imagery vividness; Durndell and Wetherick (1976) found no significant correlations.

Campos and Pérez (1989) obtained significant correlations between scores on the Visual Elaboration Scale (Slee, 1976) and the fluency, flexibility, and elaboration measures of the Torrance Tests of Creative Thinking, but did not find any significant correlations between imagery and originality. Campos and Pérez also obtained differences in creativity between high and low imagers.

Campos and González (in press) used the Betts QMI and the What Kind of Person Are You? test from Khatena and Torrance's (1976) Creative Perception Inventory, and found that imagery vividness had little load on creativity. In this study, we continue the same line of research, with the aim of evaluating the effect of imagery vividness on creativity in undergraduate students of fine arts, mathematics, and geography and history.

\section{METHOD}

\begin{abstract}
The sample comprised 1,361 undergraduates ( 509 males, 852 females) from the Universities of Santiago, Vigo, Salamanca, and the Basque Country (Spain). The students were in the 1st or 4th year of fine arts (497 subjects), mathematics (450), or geography and history (414). Their mean age was 20.4 years (range, 18-25).

All subjects completed the SAM subtest of the Creative Perception Inventory (Khatena \& Torrance, 1976), and the revision of Betts's (1909) QMI (Sheehan, 1967). The Betts QMI measures vividness of mental imagery in seven sensory modalities: visual, auditory, tactile, kinesthetic, gustatory, olfactory, and organic. Questions within the test are arranged in seven blocks of five, and require mental images, which are elicited by each question, to be rated on a seven-point scale from perfectly clear and vivid (1) to no image at all (7); low scores thus represent the most vivid imagery.
\end{abstract}

\section{RESULTS}

\section{Fine Arts Students}

Scores on all the sensory modality subscales of the Betts QMI correlated significantly with creativity (Table 1).

To determine which sensory modalities best predict creativity, we used stepwise regression analysis. Only the tactile and visual modalities, together explaining $6 \%$ of the total variance in creativity, were selected for the final equation (Table 2). 
Table 1

Pearson Correlations Between the Sensory Modalities of Betts's QMI and the SAM (Fine Arts)

\begin{tabular}{lccc}
\hline Sensory Modalities & SAM & $M$ & $S D$ \\
\hline Visual & $-.21^{*}$ & 2.49 & .85 \\
Auditory & $-.16^{*}$ & 2.76 & .97 \\
Tactile & $-.23^{*}$ & 2.65 & .86 \\
Kinesthetic & $-.15^{*}$ & 2.50 & .87 \\
Gustatory & $-.14^{*}$ & 2.84 & 1.07 \\
Olfactory & $-.15^{*}$ & 2.85 & 1.10 \\
Organic & $-.16^{*}$ & 2.49 & .96 \\
$M$ & 26.43 & & \\
$S D$ & 6.37 & & \\
\hline
\end{tabular}

${ }^{*} p<.01$.

Table 2

Stepwise Regression Analysis (Dependent Variable $=$ Creativity) (Fine Arts)

\begin{tabular}{|c|c|c|c|c|}
\hline $\begin{array}{c}\text { Variables } \\
\text { in the } \\
\text { Final Equation* }\end{array}$ & $\beta$ & $t$ & $p$ & $\begin{array}{c}\text { Percent } \\
\text { Explained } \\
\text { Variance } †\end{array}$ \\
\hline Tactile & -.17 & -3.36 & .0008 & 5.11 \\
\hline Visual & -.13 & -2.62 & .009 & 1.30 \\
\hline
\end{tabular}

${ }^{*} R=.23 . \quad \dagger R^{2}=.06$.

Table 3

Pearson Correlations Between the Sensory Modalities of Betts's QMI and the SAM (Mathematics)

\begin{tabular}{lccc}
\hline Sensory Modalities & SAM & $M$ & $S D$ \\
\hline Visual & $-.24^{*}$ & 2.52 & .81 \\
Auditory & $-.14^{*}$ & 2.94 & .86 \\
Tactile & $-.18^{*}$ & 2.87 & .79 \\
Kinesthetic & $-.22^{*}$ & 2.56 & .84 \\
Gustatory & $-.21^{*}$ & 2.93 & .91 \\
Olfactory & $-.16^{*}$ & 2.98 & 1.01 \\
Organic & $-.17^{*}$ & 2.59 & .92 \\
$M$ & 22.91 & & \\
$S D$ & 6.55 & & \\
\hline
\end{tabular}

${ }^{*} p<.01$.

Table 4

Stepwise Regression Analysis (Dependent Variable $=$ Creativity) (Mathematics)

\begin{tabular}{lcccc}
\hline $\begin{array}{c}\text { Variables } \\
\text { in the }\end{array}$ & & & & $\begin{array}{c}\text { Percent } \\
\text { Explained } \\
\text { Variance } \dagger\end{array}$ \\
Final Equation* & $\beta$ & $t$ & $p$ & 5.56 \\
\hline Visual & -.16 & -3.21 & .001 & .006 \\
Gustatory & -.13 & -2.76 & .006 & 2.43 \\
Kinesthetic & -.12 & -2.40 & .01 & 1.18 \\
\hline
\end{tabular}

$* R=.30 . \quad \dagger R^{2}=.09$.

\section{Mathematics Students}

Scores on all the sensory modalities of the Betts QMI correlated significantly with creativity (Table 3 ).

Three sensory modalities (visual, gustatory, and kinesthetic), together explaining $9 \%$ of the total variance in creativity, were selected in stepwise regression analysis (Table 4).

\section{Geography and History Students}

Scores on all the sensory modalities of the Betts QMI correlated significantly with creativity (Table 5).
Table 5

Pearson Correlations Between the Sensory Modalities of Betts's QMI and the SAM (Geography and History)

\begin{tabular}{lccr}
\hline Sensory Modalities & SAM & $M$ & $S D$ \\
\hline Visual & $-.25^{*}$ & 2.32 & .82 \\
Auditory & $-.21^{*}$ & 2.64 & .92 \\
Tactile & $-.22^{*}$ & 2.65 & .87 \\
Kinesthetic & $-.25^{*}$ & 2.51 & .97 \\
Gustatory & $-.22^{*}$ & 2.69 & .96 \\
Olfactory & $-.19^{*}$ & 2.67 & 1.03 \\
Organic & $-.14^{*}$ & 2.40 & .93 \\
$M$ & 23.48 & & \\
$S D$ & 6.98 & & \\
\hline
\end{tabular}

Table 6

Stepwise Regression Analysis (Dependent Variable $=$ Creativity) (Geography and History)

\begin{tabular}{lcccc}
\hline $\begin{array}{c}\text { Variables } \\
\text { in the }\end{array}$ & & & & $\begin{array}{c}\text { Percent } \\
\text { Explained } \\
\text { Final Equation* }\end{array}$ \\
\hline Kinesthetic & $\beta$ & $t$ & $p$ & Variance $\dagger$ \\
Visual & -.13 & -2.37 & .01 & 6.15 \\
Gustatory & -.11 & -3.01 & .002 & 2.47 \\
$* R=.31 . \quad \dagger R^{2}=.10$. & & & .04 & .90 \\
\hline$*$
\end{tabular}

Table 7

Pearson Correlations Between the Sensory Modalities of Betts's QMI and the SAM (All Subjects)

\begin{tabular}{lccc}
\hline Sensory Modalities & SAM & $M$ & $S D$ \\
\hline Visual & $-.21^{*}$ & 2.45 & .83 \\
Auditory & $-.17^{*}$ & 2.78 & .92 \\
Tactile & $-.22^{*}$ & 2.72 & .84 \\
Kinesthetic & $-.21^{*}$ & 2.52 & .89 \\
Gustatory & $-.18^{*}$ & 2.82 & .99 \\
Olfactory & $-.16^{*}$ & 2.84 & 1.05 \\
Organic & $-.16^{*}$ & 2.49 & .94 \\
$M$ & 24.37 & & \\
$S D$ & 6.81 & & \\
\hline
\end{tabular}

${ }^{*} p<.01$.

Table 8

Stepwise Regression Analysis (Dependent Variable $=$ Creativity) (All Subjects)

\begin{tabular}{lcccc}
\hline $\begin{array}{c}\text { Variables } \\
\text { in the }\end{array}$ & & & & $\begin{array}{c}\text { Percent } \\
\text { Explained } \\
\text { Final Equation* }\end{array}$ \\
\hline Tactile & $\beta$ & $t$ & $p$ & Variance $\dagger$ \\
Visual & -.12 & -3.94 & .0001 & 4.96 \\
Kinesthetic & -.13 & -4.28 & .0001 & 1.83 \\
\hline
\end{tabular}

$* R=.27 . \quad \dagger R^{2}=.07$.

Three sensory modalities (kinesthetic, visual, and gustatory), together explaining $10 \%$ of the total variance in creativity, were selected in stepwise regression analysis (Table 6).

\section{All Subjects}

When all subjects were considered together, scores on all the sensory modalities of Betts's QMI correlated significantly with creativity (Table 7).

Three sensory modalities (tactile, visual, and kinesthetic), together explaining $7 \%$ of the total variance 
in creativity, were selected in stepwise regression analysis (Table 8).

\section{DISCUSSION}

Unlike Khatena (1975), Rhodes (1981), and Campos and González (in press), we have found significant correlations between creativity and all the sensory modalities of the Betts QMI, confirming the widely held opinion that there is a relationship between imagery vividness and creativity (Campos \& Pérez, 1989; Ernest, 1977; Forisha, 1978; Schmeidler, 1965; Shaw, 1985; Sheehan et al., 1978).

Regression analysis indicated that imagery vividness explains only a small proportion ( $7 \%$ on average) of the total variance in creativity, and that, in this respect, there is little difference between students of the three disciplines studied.

In our opinion, the strength of correlation between imagery vividness and creativity is highly influenced by the type of test used (Campos \& Pérez, 1989; Shaw \& DeMers, 1986), and thus we consider further studies, employing different instruments, to be necessary.

\section{REFERENCES}

BETTS, G. H. (1909). The distribution and functions of mental imagery. New York: Teachers College Press, Columbia University.

Campos, A., \& GonzÁlez, M. A. (in press). Imagery vividness and creativity. Perceptual \& Motor Skills.

Campos, A., \& PÉrez, M. J. (1989). High and low imagers and their scores on creativity. Perceptual \& Motor Skills, 68, 403-406.

Durndell, A. J., \& WeTherick, N. E. (1976). The relation of reported imagery to cognitive performance. British Journal of Psychology, 67, 501-506.

ERNEST, C. H. (1977). Imagery ability and cognition: A critical review. Journal of Mental Imagery, 2, 181-216.

Forisha, B. D. (1978). Creativity and imagery in men and women. Perceptual \& Motor Skills, 47, 1255-1264.
Khatena, J. (1971). Something About Myself: Norms-technical manual. Huntington, WV: Marshall University.

Khatena, J. (1975). Vividness of imagery and creative self perceptions. Gifted Child Quarterly, 19, 33-37.

Khatena, J., \& Torrance, E. P. (1976). Khatena-Torrance Creative Perception Inventory. Bensenville, IL: Scholastic Testing Service.

RHODES, J. W. (1981). Relationships between vividness of mental imagery and creative thinking. Journal of Creative Behavior, 15, 90-98.

Richardson, A. (1969). Mental imagery. New York: Springer-Verlag.

SChmeidler, G. (1965). Visual imagery correlated to a measure of creativity. Journal of Consulting Psychology, 29, 78-80.

SHAw, G. A. (1985). The use of imagery by intelligent and by creative school children. Journal of General Psychology, 112, 153-171.

Shaw, G. A., \& Belmore, S. M. (1982-1983). The relationship between imagery and creativity. Imagination, Cognition \& Personality, 2, 115-123.

Shaw, G. A., \& DeMers, S. T. (1986). The relationship of imagery to originality, flexibility and fluency in creative thinking. Journal of Mental Imagery, 10, 65-74.

SheehAN, P. W. (1967). A shortened form of Betts' Questionnaire Upon Mental Imagery. Journal of Clinical Psychology, 23, 386-389.

Sheehan, P. W., McConkey, K. M., \& LaW, H. G. (1978). Imagery facilitation and performance on the Creative Imagination Scale. Journal of Mental Imagery, 2, 265-274.

SLEE, J. A. (1976). The perceptual nature of visual imagery. Unpublished doctoral dissertation, Australian National University, Canberra.

Torrance, E. P. (1974). Torrance Tests of Creative Thinking: Norms technical manual. Lexington, MA: Ginn.

TORRANCE, E. P., \& KHATENA, J. (1970). Technical-norms manual for What Kind of Person Are You? test. Athens, GA: Georgia Studies of Creative Behavior.

WILSON, S. C., \& BARBER, T. X. (1976). The Creative Imagination Scale as a measure of hypnotic responsiveness: Applications to experimental and clinical hypnosis. Medfield, MA: Medfield Foundation.

(Manuscript received June 12, 1993.) 